\title{
Right Hub Disinfection for Compliance
}

\author{
Carole Hallam
}

\begin{abstract}
The two most common causes of catheterrelated bloodstream infections (CRBSI) are contamination of the external surface of the vascular device from the patient skin (extraluminal) and contamination of the internal lumen of the catheter via the catheter hub (intraluminal). This chapter focuses on disinfection of the catheter hub, allowing the reader to consider issues relating to contamination of the catheter hubs and connectors as well as what evidence and guidance are provided to prevent intraluminal colonisation.
\end{abstract}

\section{Keywords}

Hub disinfection - Passive disinfection caps Active disinfection - Drying time Disinfectants $\cdot$ Methods for disinfecting catheter hubs

\subsection{Introduction}

Needle-free connectors (NFC) are widely used on vascular access devices to provide easy access for infusion connection while eliminating the need to use a needle, thus reducing needle-stick

C. Hallam $(\bowtie)$

Calderdale and Huddersfield NHS Foundation Trust, Huddersfield, UK injuries (Moureau and Flynn 2015). NFC are used to cap the hubs and should allow easy and effective decontamination between uses due to their flat surface design (Curran 2016). Results of a randomised clinical trial suggested that the use of NFC may reduce contamination compared to standard caps (Casey et al. 2003). However, results from a systematic review found that $33-45 \%$ of NFC were found to be contaminated (Moureau and Flynn 2015), suggesting the importance of disinfection of the needle-free connector prior to access of these devices.

\subsection{Potential Microbial Contamination and Risk of CRBSI}

Microorganisms found on the patient's skin easily contaminate the catheter hubs and are often the same organisms implicated in CRBSI such as coagulase-negative Staphylococcus and Staphylococcus aureus, enterococci, and Candida species (Loveday et al. 2014). As most vascular access devices are accessed frequently, often several times a day, there is great risk of microorganisms entering into the lumen of the catheter, therefore increasing the risk of CRBSI (Merrill et al. 2014; Loveday et al. 2014). High incidence of catheter hub colonisation has been shown to correlate with positive blood cultures (Holroyd et al. 2017). 
Once a vascular device is inserted into the blood vessel, biofilms develop rapidly from plasma proteins, platelets, and neutrophils (Donlan 2001). These biofilms form a sticky surface that allows microorganisms introduced via the catheter hub to adhere to the internal lumen of the catheter where they can multiply. Eventually, segments from the biofilm break off, and the microorganisms enter the patients' bloodstream causing a bloodstream infection (Curran 2016).

The Infusion Nurse Society (Gorski et al. 2016) Standards of Practice recognise needlefree connectors have different designs with different internal mechanisms and fluid pathways but state that there is no consensus on design of type of NFC to prevent or reduce vascular access device infections (Gorski et al. 2016). To achieve adequate disinfection of a needle-free connector, the following factors should be considered:

1. The device should not have gaps between the membrane and the housing.

2. The membrane should be smooth.

3 . The membrane should return to its initial position following access (Kelly et al. 2017).

The design selection of NFC is covered in more detail in Chap. 19.

Importantly, guidance from INS (Gorski et al. 2016), Royal College of Nursing (RCN 2016), Healthcare Infection Control Practices Advisory Committee (HICPAC) of the Centers for Disease Control and Prevention (CDC) (O'Grady et al. 2011) and Epic3 (Loveday et al. 2014) are all clear about the need to disinfect the NFC prior to each access of the device. However, consideration needs to be given as to which solution to use to decontaminate the NFC, what technique provides sufficient decontamination and optimal time required to achieve effective disinfection. These points will be considered in the rest of this chapter.

\subsection{Choice of Disinfectants}

The choice of disinfection must always be compatible with the device and should not cause damage that could affect the integrity or perfor- mance of the device (RCN 2016). Although manufacturers' guidance should be followed (Loveday et al. 2014; RCN 2016), it would seem prudent to check the guidance from the manufacturers prior to purchase to ensure it meets the regulatory standard that may be imposed either at local or national level.

Isopropyl alcohol in concentrations above $60 \%$ is an effective disinfectant against a range of organisms. It is able to rapidly kill organisms, but its activity time is very limited because it evaporates quickly on surfaces (CDC 2008). Alcohol is deactivated by the presence of organic matter such as blood, pus, serum and faecal matter, as these interfere with the properties of the disinfectant (WHO 2014). Alcohol is known to damage some surfaces including plastics and rubber (CDC 2008), but most manufacturers have ensured that catheter hubs and NFC are chemically compatible with alcohol (Loveday et al. 2014).

Chlorhexidine and povidone-iodine are both recognised as effective skin disinfectants for vascular access device insertion and are known to have residual activity (Chopra and Saint 2015), allowing for continued killing effect after the alcohol has dried. Loveday et al. (2014) recognised the lack of good evidence supporting disinfection of hubs and connectors, and therefore the Epic3 guidance was based on expert consensus following review of experimental studies.

More recently Flynn et al. (2017) found chlorhexidine gluconate swabs $(2 \%$ chlorhexidine gluconate and $70 \%$ alcohol) to be more effective than alcohol swabs at reducing the number of organisms on NFC. However, these authors did highlight that it is unknown if there is any residual disinfectant activity or damage to the material of the NFC or if any traces of the chlorhexidine would get injected into the bloodstream. Chlorhexidine sensitivity is a known risk in some patients, and therefore alternative disinfectants should be available such as povidone-iodine (Loveday et al. 2014; RCN 2016).

Guidance in various countries differs, for example, Health Protection Scotland states 70\% alcohol in their guidance and states that the 
method of cleaning is more important than the disinfectant (Health Protection Scotland 2012). American guidance (O'Grady et al. 2011; Gorski et al. 2016) states that chlorhexidine, povidoneiodine, or alcohol $70 \%$ should be used for the disinfection of the hubs and NFC with the guidance in England (Loveday et al. 2014, RCN 2016) stating the use of $2 \%$ chlorhexidine gluconate in $70 \%$ alcohol.

Finally, prior to making any decisions of what disinfectants to use for decontaminating the catheter hub and NFC, determine whether there is any local or national regulatory guidance that should be followed.

\subsection{Disinfection Methods}

Once the disinfectant has been selected to decontaminate the hubs and NFC, the disinfection technique needs to be decided upon; currently there is no defined best method (Zhang et al. 2016). There are two methods to decontaminate the hubs and NFC: active disinfection and passive disinfection (Curran 2016; Kelly et al. 2017).

Active disinfection is performed using a wipe to mechanically loosen the microorganisms allowing the disinfectant to destroy the microorganisms (Curran 2016). This procedure is often referred to as 'scrubbing the hub' (O'Grady et al. 2011; Cameron-Watson 2016; Kelly et al. 2017). Regardless of the disinfectant solution, the time spent on disinfection of the hub or NFC is deemed the most important (Moureau and Flynn 2015).

The active method for decontaminating the hubs is open to variation in both the technique used by the individual and the actual time spent carrying out the procedure (Cameron-Watson 2016). Arguably, it could be suggested that busy healthcare workers don't have enough time to spend decontaminating these hubs for the length of time necessary to achieve effective disinfection (Merrill et al. 2014; Cameron-Watson 2016).

Passive disinfection is achieved using alcohol-impregnated catheter hub protection caps (Gorski et al. 2016). These disinfection caps contain a sponge impregnated with alcohol that can be attached to the NFC, thus protecting the access point from contamination as well as providing disinfection (Flynn et al. 2015; Cameron-Watson 2016; Curran 2016). These disinfection caps are single-use items and must be changed following each use (Sweet et al. 2012; Kelly et al. 2017).

There is some evidence that these disinfection caps can reduce contamination of the NFC and reduce rates of CRBSI (Sweet et al. 2012; Loveday et al. 2014; Cameron-Watson 2016). The advantage of the disinfection caps is that once screwed into place, the alcohol covers the entire surface of the NFC providing continuous decontamination (Flynn et al. 2015; Curran 2016). In one study, the use of disinfection caps was associated with a $40 \%$ decrease in central line-associated bloodstream infections (Merrill et al. 2014). In addition, the use of a disinfection cap provides a standardised approach to disinfection (Curran 2016; Kelly et al. 2017).

\subsection{Optimal Time for Hub Disinfection}

Although disinfecting time is deemed important, there is a lack of clarity for the specific time required to reach optimal disinfection (Merrill et al. 2014; Moureau and Flynn 2015). Some studies have suggested as little as $5 \mathrm{~s}$ to be effective in disinfection of the NFC (Rupp et al. 2012; Flynn et al. 2017) but specify only if not heavily contaminated or the latter authors found a reduction only with alcohol and chlorhexidine as opposed to any other disinfectants. The obvious difficulty in assessing whether or not the NFC was heavily contaminated would be the fact that microorganisms are not visible to the naked eye; therefore, this would almost be a best guess situation (Curran 2016).

In the Epic3 guidelines, the lack of clear evidence for optimal disinfection time was recognised; therefore, their choice of a minimum of $15 \mathrm{~s}$ for disinfection was selected using expert opinion based on evidence from skin cleansing prior to insertion studies and experimental studies (Loveday et al. 2014). More recent evidence in an experimental study suggests that $30 \mathrm{~s}$ is the 
Table 18.1 Summary table of guidance for disinfection of hubs and NFC

\begin{tabular}{|c|c|c|c|}
\hline Guidance & Specified disinfectant & $\begin{array}{l}\text { Specified } \\
\text { time }\end{array}$ & $\begin{array}{l}\text { Type of } \\
\text { action }\end{array}$ \\
\hline $\begin{array}{l}\text { Healthcare Infection Control } \\
\text { Practices Advisory Committee } \\
\text { (O'Grady et al. 2011) }\end{array}$ & Chlorhexidine, povidone-iodine or $70 \%$ alcohol & $\begin{array}{l}\text { Not } \\
\text { specified }\end{array}$ & Active \\
\hline Health Protection Scotland (2012) & $70 \%$ isopropyl alcohol & $15 \mathrm{~s}$ & Active \\
\hline Queensland Government (2015) & $70 \%$ alcohol or $2 \%$ alcoholic chlorhexidine & $15 \mathrm{~s}$ & Active \\
\hline Epic3 (Loveday et al. 2014) & $\begin{array}{l}2 \% \text { chlorhexidine gluconate in } 70 \% \text { isopropyl } \\
\text { alcohol (or povidone-iodine in alcohol for patients } \\
\text { with sensitivity to chlorhexidine) }\end{array}$ & $15 \mathrm{~s}$ & Active \\
\hline $\begin{array}{l}\text { Society of Healthcare } \\
\text { Epidemiology of America } \\
\text { (Marschall et al. 2014) }\end{array}$ & $\begin{array}{l}\text { Alcoholic chlorhexidine preparation, } 70 \% \text { alcohol, } \\
\text { or povidone-iodine }\end{array}$ & $5 \mathrm{~s}$ & Active \\
\hline $\begin{array}{l}\text { Association for Professional in } \\
\text { Infection Control and } \\
\text { Epidemiology (APIC 2015) }\end{array}$ & Chlorhexidine, povidone-iodine, or $70 \%$ alcohol & $15 \mathrm{~s}$ & Active \\
\hline $\begin{array}{l}\text { International Federation of } \\
\text { Infection Control (IFIC) (DeVries } \\
\text { 2016) }\end{array}$ & $70 \%$ isopropyl alcohol & $\begin{array}{l}\text { Not } \\
\text { specified }\end{array}$ & Active \\
\hline $\begin{array}{l}\text { Infusion Nurses Society (Gorski } \\
\text { et al. 2016) }\end{array}$ & $\begin{array}{l}70 \% \text { isopropyl alcohol, povidone-iodine or }>0.5 \% \\
\text { chlorhexidine in alcohol }\end{array}$ & $5-60 \mathrm{~s}$ & $\begin{array}{l}\text { Active/ } \\
\text { passive }\end{array}$ \\
\hline $\begin{array}{l}\text { Royal College of Nursing (RCN } \\
\text { 2016) }\end{array}$ & $\begin{array}{l}2 \% \text { chlorhexidine gluconate in } 70 \% \text { isopropyl } \\
\text { alcohol }\end{array}$ & $\begin{array}{l}\text { Not } \\
\text { specified }\end{array}$ & $\begin{array}{l}\text { Active/ } \\
\text { passive }\end{array}$ \\
\hline
\end{tabular}

ideal disinfection time to adequately decontaminate the NFC (Flynn et al. 2017).

The INS (2016) guidance is the only guidance that specifically states the need to disinfect the NFC prior to each subsequent administration when multiple accesses are required via the vascular device. They suggest a 5-15 s disinfection time for each subsequent access (Gorski et al. 2016).

In addition to the time required to effectively disinfect the NFC, the drying time to allow for the full activity of the disinfectant must be considered (DeVries 2016). Most of the guidance states 'allow the disinfectant to dry' as opposed to stating a specified time (O'Grady et al. 2011; DeVries 2016; Gorski et al. 2016; RCN 2016). Other recommendations state that the disinfectant should be visibly dry, and drying time could exceed 30 seconds (Loveday et al. 2014).

Further research is required to provide the optimal time for disinfection of hubs and NFC prior to access (Loveday et al. 2014; Gorski et al. 2016). Local, national or manufacturer's guidance mandates the time required to disinfect the hubs and NFC and should always be followed (Moureau and Flynn 2015; RCN 2016).
A summary of the published national guidance for disinfection of hubs and NFC is provided in Table 18.1 below.

\subsection{Changing Needle-Free Connectors}

The interval for changing NFC should be in accordance with the manufacturer's guidance and can vary between $72 \mathrm{~h}$ and 7 days (RCN 2016; Gorski et al. 2016; Kelly et al. 2017). However, there is no evidence to suggest the need to change NFC more frequently than $96 \mathrm{~h}$ (Sandora et al. 2014). Most importantly, an aseptic technique should be adopted when changing the NFC (APIC 2015). This can be adequately achieved using Standard-ANTT (Flynn et al. 2015).

Additionally, the NFC should be replaced if disconnected for any reason, if there is visible blood or debris in the NFC, or prior to obtaining a blood sample for culture (Gorski et al. 2016). NFC can become more difficult to disinfect once contaminated with blood, suggesting the NFC be discarded following blood 
draws and transfusions (Flynn et al. 2017). However, as of yet, this has not been included in national guidance.

\subsection{Compliance with Standards}

It is clear from the evidence that there are two critical areas of practice to prevent microbial contamination via the catheter hub: use of an aseptic technique including hand hygiene and effective disinfection of the NFC prior to access of the vascular device (Warren et al. 2006; O'Grady et al. 2011; Loveday et al. 2014).

The use of Aseptic Non Touch Technique (ANTT) provides a standardised approach to aseptic technique by providing easy-to-follow steps making compliance easier (Rowley and Clare 2009; Loveday et al. 2014). The essential components of an aseptic technique include hand hygiene and use of personal protective equipment (Rowley and Clare 2009; O'Grady et al. 2011; Loveday et al. 2014).

Despite the clear guidance for use of an aseptic technique, compliance has been reported as poor (Moureau 2014; Flynn et al. 2015). Poor hand hygiene can result in the spread of microorganisms between patients and results in a direct risk factor for vascular access device infections (Zhang et al. 2016). Improving hand hygiene requires a multi-modal approach (WHO 2009) and includes behavioural changes such as empowering nurses to be able to halt practices where physicians or other colleagues have breached hand hygiene (Chopra and Saint 2015).

Disinfection of the catheter hubs is considered central to patient safety (Kelly et al. 2017), yet compliance has been noted to be unacceptably low, particularly with timing (Moureau 2014; Caspari et al. 2017). One study showed up to an $80 \%$ failure rate of disinfecting key parts such as NFC (Rowley and Clare 2009).

Human factors should be considered to improve compliance with hub disinfection. Ensuring that disinfection wipes or caps are readily available at the point of use prevents busy staff from wasting valuable time searching for the equipment (Gorski et al. 2016). Additionally, the use of disinfection caps can make the disinfection method easier as it removes the need to time the process. Additionally, observation of practice and audit of compliance could become easier (Merrill et al. 2014; Cameron-Watson 2016).

A recent study found that both education and introduction of timing devices increased the compliance of recommended timing for disinfection of vascular access devices. These authors concluded that timing devices such as a timer or musical button should be implemented when there is a requirement of timebased procedures to account for human factors (Caspari et al. 2017).

Performance and quality improvement processes are essential to improving and maintaining compliance with practice standards in vascular access care (O'Grady et al. 2011). These should include continuing professional education, accessible protocols, audit with feedback of compliance with practice guidelines and visual prompts and reminders (Loveday et al. 2014).

\section{Case Study}

You have just started a new job at your local hospital. Since you have never worked there before, what do you need to consider prior to disinfecting the needleless connector prior to administering IV drugs to a patient?

\section{Case Study}

Carly is a 29-year old female who has undergone major resection of her bowel due to Crohn's disease and is now preparing to go home. She has a tunnelled central venous catheter for parenteral nutrition (PN) which she will be administering herself following discharge. What advice will you give her about how to disinfect the needle connector prior to connecting the $\mathrm{PN}$ ? 


\section{Summary of Key Points}

1. Hands must be decontaminated prior to access and manipulation of catheter hubs and NC.

2. An aseptic technique should be used for accessing and changing needleless connectors.

3. All vascular access points should be disinfected prior to access with a disinfectant compatible with the device.

4. Use either a scrub the hub technique to disinfect the NC or use a passive technique with alcohol-impregnated protective cap.

5. Consider human factors to achieve high levels of compliance.

6. Check manufacturer's guidance for the management of $\mathrm{NC}$, preferably before purchase.

7. Ensure local and national guidance is followed.

8. Provide regular audit with feedback of compliance with standards.

\section{References}

Association for Professional in Infection Control and Epidemiology. APIC implementation guide: guide to preventing central line associated blood stream infections. 2015. http://apic.org/Resource_/ TinyMceFileManager/2015/APIC_CLABSI_WEB.pdf.

Cameron-Watson C. Port protectors in clinical practice: an audit. Br J Nurs. 2016;25(8):S25-31.

Casey AL, Worthington T, Lambert PA, Quinn D, Faroqui $\mathrm{MH}$, Elliott TSJ. A randomized, prospective clinical trial to assess the potential infection risk associated with the PosiFlow ${ }^{\circledR}$ needleless connector. J Hosp Infect. 2003;54:288-93.

Caspari L, Epstein E, Blackman A, Jin L, Kaufman DA. Human factors related to time dependant infection control measures "scrub the hub" for venous catheters and feeding tubes. Am J Infect Control. 2017;45(6):648 51. https://doi.org/10.1016/j.ajic.2017.01.004. (Epub ahead of print).

CentersforDiseaseControlandPrevention(CDC)Healthcare Infection Control Practices Advisory Committee (HICPAC). Guideline for disinfection and sterilisation in healthcare facilities. 2008. https://www.cdc.gov/ hicpac/disinfection_sterilization/6_0disinfection.html.
Chopra V, Saint S. Vascular catheter infections: time to get technical. Lancet. 2015;386:2034-6.

Curran E. Needleless connectors: the vascular access catheter's microbial gatekeeper. J Infect Prev. 2016;17(5):234-40.

DeVries C. Prevention of intravascular device-associated infections. Basic concepts. Chapter 17. International Federation of Infection Control. 2016. http://theific. org/wp-content/uploads/2016/04/17-IV_2016.pdf.

Donlan RM. Biofilms and device-associated infections. Emerg Infect Dis. 2001;7:277-81.

Flynn J, Keogh S, Gavin N. Sterile v aseptic non-touch technique for needle-less connector care on central venous access devices in a bone marrow transplant population: a comparative study. Eur J Oncol Nurs. 2015;19:694-700.

Flynn J, Richard C, Keogh S, Zhang L. Alcohol caps or alcohol with and without chlorhexidine: an in vitro study of 648 episodes of intravenous device needless connector decontamination. Infect Control Hosp Epidemiol. 2017;38(5):617-9.

Gorski L, Hadaway L, Hagle M, McGoldrick M, Orr M, Doellman D. Infusion therapy standards of practice. J Infus Ther. 2016;39:1S.

Health Protection Scotland. Targeted literature review: what are the key infection prevention and control recommendations to inform peripheral vascular catheter (PVC) maintenance care quality improvement tool? 2012.

Holroyd JL, Vasiloppoulos T, Rand K, Fahy B. Incidence of central venous catheter hub contamination. J Crit Care. 2017;39:162-8.

Kelly L, Jones T, Kirkham S. Needlefree devices: keeping the system closed. Br J Nurs. 2017;26(2):S14-9.

Loveday HP, Wilson JA, Pratt RJ, Golsorkhi M, Tingle A, Bak A, Browne J, Prieto J, Wilcox M. Epic3: national evidence-based guidelines for preventing healthcareassociated infections in NHS hospitals. J Hosp Infect. 2014;S86:S1-S70.

Marschall J, Mermel LA, Fakih M, Hadaway L, Kallen A, O'Grady N, Pettis A, Rupp ME, Sandora T, Maragakis LL, Yokoe D. Strategies to prevent central lineassociated bloodstream infections in acute care hospitals: 2014 update. Infect Control Hosp Epidemiol. 2014;35(7):753-71. http://digitalcommons.wustl.edu/ open_access_pubs/3453

Merrill KC, Sumner S, Linford L, Taylor C, Macintosh C. Impact of universal disinfectant cap implementation on central-line associated bloodstream infections. Am J Infect Control. 2014;42:1274-7.

Moureau NL. Catheter associated bloodstream infection prevention: what is missing? $\mathrm{Br} \mathrm{J}$ Healthc Manag. 2014;20(11):502-10.

Moureau NL, Flynn J. Disinfection of needless connector hubs: clinical evidence systematic review. Nurs Res Pract. 2015;2015:796762.

O'Grady NP, Alexander M, Burns LA, Dellinger EP, Garland J, Heard SO, Lipsett PA, Masur H, Mermel LA, Pearson ML, Raad II, Randolph AG, Rupp ME, 
Saint S, the Healthcare Infection Control Practices Advisory Committee (HICPAC). Guidelines for the prevention of intravascular catheter-related infections. Clin Infect Dis. 2011;52:e162-93.

Queensland Government. Guideline: peripheral intravenous catheter (PIVC). Queensland Government. 2015. https://www.health.qld.gov.au/_data/assets/ pdf_file/0025/444490/icare-pivc-guideline.pdf.

Rowley S, Clare S. Improving standards of aseptic practice through ANTT trust-wide implementation process: a matter of prioritisation and care. J Infect Prev. 2009;10(1 Supplement):S18-23.

Royal College of Nursing. Standards for infusion therapy. 4th ed. London: RCN; 2016.

Rupp ME, Yu S, Huerta T, Cavaleri RJ, Alter F, Fey FD, Van Schooneveld T, Anderson JR. Adequate disinfection of a split-septum needleless intravascular connector with a 5-second alcohol scrub. Infect Control Hosp Epidemiol. 2012;33:661-5.

Sandora TJ, Graham DA, Conway M, Dobson B, PotterBynoe G, Margossain SP. Impact of needless connector change frequency on central line-associated. Am J Infect Control. 2014;42(5):485-9.

Sweet MA, Cumpston A, Briggs F, Craig M, Harmadini M. Impact of alcohol-impregnated port protectors and needleless neutral pressure connectors on central line-associated bloodstream infections and contamination of blood cultures in an inpatient oncology unit. Am J Infect Control. 2012;40:931-4.

Warren DK, Cosgrove SE, Diekema DJ, Zuccotti G, Climo MW, Bolon MK, Tokars JI, Noskin GA, Wong ES, Sepkowitz KA, Herwaldt LA, Perl TM, Solomon SL, Fraser VJ, Prevention Epicenter Program. A multicentre intervention to prevent catheter-associated bloodstream infections. Infect Control Hosp Epidemiol. 2006;27(7):662-9.

World Health Organisation. A guide to the implementation of the WHO multimodal hand hygiene improvement strategy. 2009. http://apps.who.int/iris/ bitstream/10665/70030/1/WHO_IER_PSP_2009.02_ eng.pdf.

World Health Organisation. Infection prevention and control of epidemic-and pandemic-prone acute respiratory infections in healthcare. Geneva: WHO; 2014.

Zhang L, Cao S, Marsh N, Ray-Barruel G, Flynn J, Larsen E, Richard CM. Infection risks associated with peripheral vascular catheters. J Infect Prev. 2016;17(5):207-13.

Open Access This chapter is licensed under the terms of the Creative Commons Attribution 4.0 International License (http://creativecommons.org/licenses/by/4.0/), which permits use, sharing, adaptation, distribution and reproduction in any medium or format, as long as you give appropriate credit to the original author(s) and the source, provide a link to the Creative Commons license and indicate if changes were made.

The images or other third party material in this chapter are included in the chapter's Creative Commons license, unless indicated otherwise in a credit line to the material. If material is not included in the chapter's Creative Commons license and your intended use is not permitted by statutory regulation or exceeds the permitted use, you will need to obtain permission directly from the copyright holder. 